\title{
Model Studies on Heterogeneous Catalysts at the Atomic Scale
}

Hans-Joachim Freund", Shamil Shaikhutdinov, and Niklas Nilius

Fritz Haber Institute of the Max Planck Society, Faradayweg 4-6, 14195 Berlin, Germany

\section{Table of Content}

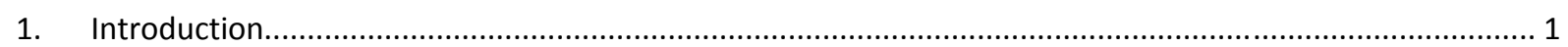

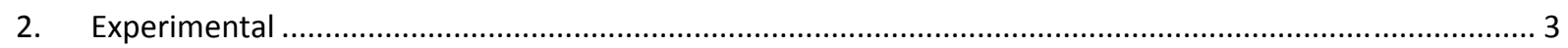

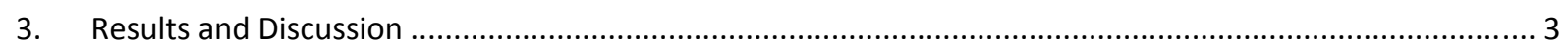

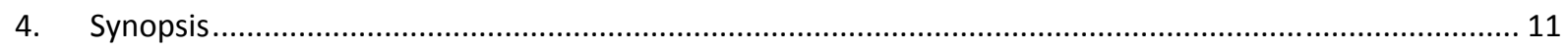

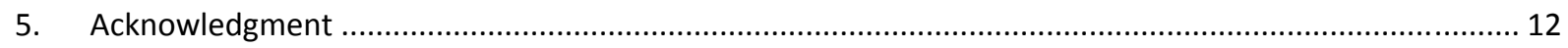

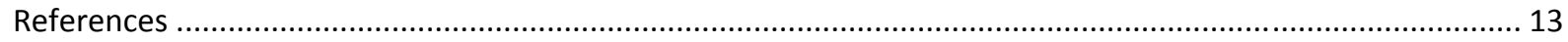

\section{Abstract}

Thin single crystalline oxide films comprise perfect supports to grow nanoparticles of metals and other catalytically relevant materials. The model systems thus created can be thoroughly investigated with respect to structure and/or chemical activity applying both, the techniques of surface science under ultrahigh vacuum conditions as well as the traditional techniques applied in catalysis to study chemical kinetics under ambient conditions. We discuss here in particular the oxidation of methanol to formaldehyde on ceria supported vanadia nanoclusters as well as the effect of transition-metal dopants in single crystalline oxides, such as $\mathrm{CaO}$, on the activation of molecular oxygen.

\section{Keywords}

Heterogeneous Catalysis, Oxidation, Oxygen Activation, Dopants

\section{Introduction}

Oxide surfaces are often used as catalysts in oxidation reactions [1]. We set out to design model systems to study oxidation catalysis on hydrocarbons and alcohols on such surfaces. Those model systems are based on well-ordered crystalline thin oxide films grown on metal single crystals using the rules of epitaxial growth. There are a number of reviews available on

\footnotetext{
*) freund@fhi-berlin.mpg.de
} 
various aspects of those thin-film-based model systems [2-5]. The main advantage of using this approach is the fact that we may use the toolbox of surface science to study those systems at the atomic level, employing scanning tunneling microscopy and variants, as well as spectroscopic techniques based on charged information carriers because those systems do not show charging.

Also, because of the growth on a metal support, which acts as a mirror, we are in a position to apply reflection infrared spectroscopy [6]. By varying the film thickness we may study the bulk material or create new systems where the underlying metal co-determines the properties [7,8]. Fig. 1 represents a schematic diagram of an oxidation reaction on a bulk oxide surface taken adapted from Jersey Haber's chapter on oxidation within the Handbook of Heterogeneous Catalysis [9]. Here, the equilibrium (chemical potential) between oxygen molecules in the gas phase and the oxide is considered. Elementary steps are indicated that provide a rationale for the transformation of a gas phase species into oxygen anions in the solid oxide. Traditionally, one distinguishes between electrophilic oxygen on the surface and nucleophilic lattice oxygen. The electrophilic oxygen is believed to be responsible for complete oxidation to carbondioxide and water, while the nucleophilic oxygen is responsible for selective oxidation. In the case of lattice oxygen, the concept of site isolation, i.e. spatial separation of an ensemble of lattice oxygen anions, has been introduced by Grasselli and Calahan $[10,11]$, and is held responsible for the specific oxidation behavior. This is indicated in Fig. 2 where different lattice oxygen ensembles schematically indicate a typical reaction that may be induced by specific arrangements. It is exemplified for the oxidation of propylene. Recently, further concepts have been introduced. A concept, relating oxidation reaction energetics to partial reaction descriptors, was recently introduced by Joachim Sauer, and we will make use of it when we discuss methanol oxidation on ceria supported vanadia catalysts $[12,13]$. Another, even more general concept on acid-base pair formation through modified oxide surfaces was proposed by Horia Metiu, enabling also a more systematic approach of the influence of dopants [14]. This proposal was recently taken up by the Häkkinen group and quantified for Mo dopants in $\mathrm{CaO}$, a system we will be dealing with in detail in the present paper [15]. Of particular interest are oxygen vacancies in the system, because they control, on one hand, the site isolation on the surface, and, on the other hand, the mobility of oxygen and electrons in the lattice [8]. Their concentration as well as their 
charge state may be controlled by the concentration of dopants [16]. In the present paper we will discuss two examples for the influence of dopants by studying the activity of very small vanadia particles deposited onto a ceria surface with respect to methanol oxidation [17], and the influence of Mo dopants within $\mathrm{CaO}$ onto adsorption of oxygen from the gas phase [18].

\section{Experimental}

The experiments have been performed in three custom made ultrahigh vacuum systems equipped with preparation chambers and the following analytical tools: scanning tunneling microscopy at room and liquid helium temperatures, $x$-ray photoelectron spectroscopy, synchrotron photoemission studies, infrared spectroscopy, and temperature programmed desorption. The experimental details are given in the papers cited and briefly discussed in the respective sections.

\section{Results and Discussion}

Fig. 3 shows a wide scan STM image of a $\mathrm{CeO}_{2}(111)$ surface grown as a thin film (ca $3 \mathrm{~nm}$ in thickness) on a Ru(0001) single crystal [17]. The inset reveals the atomic structure of the surface. Vanadium was deposited on the ceria films cooled to $\sim 150 \mathrm{~K}$ and then annealed to room temperature for 10 minutes in $10^{-6}$ mbar of $\mathrm{O}_{2}$. STM images in Fig. 4 revealed that the number, and in particular the size of protrusions changes as the amount of vanadium increased. The spectroscopic and microscopic information revealed further that we are preparing surfaces exposing vanadia monomers, distinct oligomers and islands. Moreover, the vanadia seems to be wetting the surface forming monolayer structures [19]. This finding was a first proof obtained by real space imaging, that, indeed, a monolayer oxide may be formed on an oxide support. The spectroscopic information shown in Fig. 4 clearly shows that the vanadia particles contain vanadyl $(V=O)$ bonds, with the characteristic vibrational band around $1000 \mathrm{~cm}^{-1}$, which shifts to higher frequencies when the particle size increases. This is fully compatible with interconnected $\mathrm{VO}_{4}$ tetrahedra (vanadyl bonds perpendicular to the surface), where coupling of the dynamic dipoles shifts the vibrations to higher frequencies as the number of vanadyl bonds increases. This represents the first direct structure-spectroscopy relation for those materials, and disagrees with previous assumptions on those relations [20-26]. The photoelectron spectra recorded for the same 
set of preparations exhibits further interesting structure-property relations: The V2p spectra of the vanadia deposits reveal an oxidation state of $\mathrm{V}^{5+}$ [27], compatible with a fourfold coordinated vanadyl containing species and indicating that the support is actively involved in determining the electronic structure through redox processes. As the coverage increases V2p intensities increase but the local electronic structure does not change until the second layer starts to be populated as shown by STM [17], and V2p bands characteristic of $\mathrm{V}^{3+}$ appear in the spectra, revealing considerable changes in the electronic structure. The valence band photoemission features are only modified moderately, except the feature between the valence band and the Fermi-energy, which increases as the vanadia loading increases. This feature is characteristic for $\mathrm{Ce}^{3+}$, i.e. for the filling of the $\mathrm{Ce} 4 \mathrm{f}$ states in ceria [28], forming as the vanadia binds to the substrate and uses oxygen from the ceria by producing oxygen vacancies.

The Sauer group has theoretically described the binding of vanadia monomers on the ceria surface using density functional calculations [17]. Their results are in very good agreement with the microscopic and spectroscopic information, and allow, beyond the possibilities of the experiment, predictions on the stability of vanadia species on the surface. A quantity of particular importance for the thermal stability of the smallest aggregates is their tendency to diffuse across the surface and to combine with co-adsorbed particles to form larger aggregates. The calculations [29] indicate a rather high diffusion barrier for vanadia monomers, which turns out to be of key importance to understand the temperature programmed reaction data presented in Fig. 5 for the oxidation of methanol to formaldehyde [13]. The traces from top to bottom refer to pure $\mathrm{CeO}_{2}(111)$ followed by increasing vanadia coverage. The solid lines represent the formaldehyde mass and the dotted traces mark the main fragment from methanol. Clearly, pure $\mathrm{CeO}_{2}$ is active but it produces the aldehyde at temperatures around $565 \mathrm{~K}$. When vanadia is present on the surface three peaks are observed. The one at highest temperature $(\gamma)$, between $550-600 \mathrm{~K}$, correlates with the one on clean ceria. The one at $450-500 \mathrm{~K}(\beta)$ increases in relative intensity as the vanadia coverage increases, and is thus associated with larger vanadia aggregates, while the lowest temperature peak $(\alpha)$ near $350 \mathrm{~K}$, must be due to the smallest aggregates of vanadia. When ramping the temperature the vanadia almost certainly acquires some mobility, though the barrier is high as outlined above, so that the relative peak 
intensity cannot represent the abundance of the species. But the fact that all peaks are observed indicates the relatively high stability of the various species, in line with the qualitative picture evolving from the DFT calculations. Our conclusion is that the smallest vanadia aggregates lead to activity at the lowest temperature, while polymeric species only show activity at higher temperature. It also varies considerably as we change the nature of the support, that is from ceria to alumina [30], in line with recent catalytic studies on powdered monolayer vanadia catalysts [30]. With this we conclude the discussion of the first example and now turn to the discussion of the influence of dopants within the lattice of simple oxides and their influence on oxygen adsorption.

There are not many studies in the surface science literature reported on adsorption of oxygen on oxide surfaces [31]. One reason is, of course, that many techniques do not allow to differentiate between the oxygen already present in the oxide and the adsorbed species. Studies using isotopically labeled oxygen species, however, reveal some aspects of oxygen chemistry on oxide surfaces, in particular, the intermixture of oxygen from the gas phase and oxygen in the oxide lattice [32]. In investigations on the Mars - van Krevelen mechanism those studies play an important role. In the case of group V and VI transition metal oxides, i.e. chromia, molybdena, vanadia, niobia, there are oxide phases that do not contain doubly bonded surface oxygen species in the bulk but may form such species on the surface upon exposure to oxygen from the gas phase. Alternatively, oxygen may be liberated from the phase below the oxide film, for example from a metal single crystal that contains dissolved oxygen that diffuses through the film to form adsorbed species on the surface. Those species may be easily identified through their characteristic vibrational frequencies, which render them very different from oxide phonons. In connection with studies of this kind we had probed the binding of molecular oxygen on vanadium-sesquioxide using infrared spectroscopy in comparison with DFT calculations [31]. The result of those investigations was the identification of adsorbed molecular oxygen as the precursor for atomic oxygen bound as vanadyl on the $\mathrm{V}_{2} \mathrm{O}_{3}$ surface. In this case the vanadium ions in the surface of the vanadium-sesquioxide are chemically unsaturated and try to complete their coordination environment by binding the oxygen atoms as vanadyl groups. In the next example binding of oxygen is triggered by a different mechanism, which we will discuss in the following. 
Let us consider a simple oxide of sodium chloride structure, and its (100) surface. Ideally, the surface contains the same number of cations and anions arranged in a checkerboard. Molecular oxygen will be bound rather weakly to this surface, held basically through van der Waals forces. DFT calculations for $\mathrm{O}_{2}$ on $\mathrm{CaO}(100)$ reveal that $\mathrm{O}_{2}$ is bond by $13 \mathrm{kJmol}^{-1}$ with $16 \mathrm{kJmol}^{-1}$ of dispersive binding reduced by $3 \mathrm{kJmol}^{-1}$ of repulsion [18]. There is no driving force for charge rearrangement for such an adsorbate. However, if such a surface is exposed to neutral atomic oxygen or atomic oxygen anions, binding occurs depending on the proper spin state of the atomic species. For example, neutral atomic oxygen may interact with an $\mathrm{MgO}(100)$ surface via formation of a peroxo species which is oriented perpendicular to the surface plane $[33,34]$. While those considerations apply to the ideally terminated surface, the situation becomes more complex if defects are introduced into the surface. The most common defects are color centers, where we differentiate between $\mathrm{F}^{0}, \mathrm{~F}^{+}$, and $\mathrm{F}^{2+}$ centers, depending on the number of missing electrons with respect to an $\mathrm{O}^{2-}$ site. With this nomenclature, a $\mathrm{F}^{0}$ center holds two electrons, an $\mathrm{F}^{+}$center one, and a $\mathrm{F}^{2+}$ center no electrons [8]. Many of those defects have been well characterized by their energetic position in the band gap [8] and concomitants by their spectroscopic fingerprints but they have also been imaged with scanning tunneling microscopy or atomic force microscopy [35]. They may be formed by chemical means or by electron bombardment. These color centers act as electron sources or electron traps, and, in the case of $\mathrm{F}^{0}$ and $\mathrm{F}^{+}$facilitate the formation of anionic species on such defected surfaces depending on the electron affinity of the adsorbate. Water, for example will interact with such surfaces by dissociation filling the defect and forming hydroxyls on the surface concomitantly [8]. Moreover, electronegative metals, such as $\mathrm{Au}$, may pick up the electrons and charge up. This, in turn, will lead to characteristic chemistry on such surfaces $[36,16]$. The formation of defects may also be triggered by dopants in the oxide. Consider, for example, a transition metal ion of appropriate size and equivalent charge state to substitute for a cation in a simple oxide of the kind discussed above. If this transition metal ion exists in another, higher charge state that may be formed without large energy requirements, then the charge imbalance may be compensated through the formation of a of a cation $\left(V_{M}\right)$ defects [36], which in turn control the chemistry of the system. In real systems, electron traps that provoke a spontaneous charge drain from the impurity ion to the defect might be present. The existence of overvalent dopants, for example, is known to increase the number of $V_{M}$ defects in the oxide 
lattice, as demonstrated by paramagnetic resonance and optical spectroscopy. Each $V_{M}$ center produces two holes in the $2 p$ states of nearby $O$ ions that are filled by the high-lying d-electrons of the TM impurity, according to the reaction

$2 \mathrm{TM}^{2+}+\mathrm{V}_{\mathrm{M}}+2 \mathrm{O}^{-} \rightarrow 2 \mathrm{TM}^{3+}+\mathrm{V}_{\mathrm{M}}+2 \mathrm{O}^{2-}$

In this reaction, two twofold positively charged TM-ions are oxidized, while two holes in the O2p states of adjacent oxygen get filled with the released electrons. Given the high energy of the initially filled defect state and the low energy of the initially empty holes states, this charge-transfer reaction is energetically highly favourable.

By those means, energetically unfavorable defect states in the band gap are emptied, and the total energy of the system becomes lower. DFT calculations by Pacchioni's group revealed that the formation energy of a $V_{M}$ defect in the presence of two TM dopants decreases from $\sim 8 \mathrm{eV}$ in stoichiometric $\mathrm{MgO}$ and $\mathrm{CaO}$ to 0.97 (1.68) eV in the cation-doped MgO: $\mathrm{Cr}$ (CaO:Mo) systems, respectively. The formation of $\mathrm{V}_{\mathrm{M}}$ defects is thus expected to occur in our doped oxides, especially as the samples are annealed to $1000 \mathrm{~K}$ during preparation. The Mo insertion into the $\mathrm{CaO}$ film occurs via diffusion of Mo ions from the Mo(001) single crystal, used as support in our study. The process is thermally activated and starts at around $1000 \mathrm{~K}$ sample temperature. CaO films annealed to this or lower temperature have thus a low dopant concentration, while films annealed to $1100 \mathrm{~K}$ and above are Mo-rich. The actual Mo concentration is not homogenous inside the film but depends on the distance from the CaO-Mo interface. Whereas in the interface layer, up to $25 \%$ of all cationic species are replaced by Mo ions, this number drops to zero in $25 \mathrm{ML}$ thick films annealed to $1000 \mathrm{~K}$. The desired Mo concentration in a near-surface region can, therefore, be tuned either via the film thickness or the annealing temperature. It is probed with XPS or alternatively with STM imaging and spectroscopy. For Mo-rich preparations, the typical density of Mo dopants per layer in a near region amounts to $1 \times 10^{14}-1 \times 10^{15} \mathrm{~m}^{2}$.

The STM topographies indeed displayed atom-sized depressions in the oxide surface, the density of which scaled with the dopant concentration as shown in Fig. 6 [37]. Moreover, the surface density of those vacancies was found to be higher in $\mathrm{MgO}$ than in $\mathrm{CaO}$ films at similar doping levels, reflecting the higher $V_{M}$ formation energy in the latter case. Additional electron traps are known to be present along the dislocation lines of the $\mathrm{MgO}$ and $\mathrm{CaO}$ films [38], which render a more quantitative discussion at this point difficult. By dosing the 
dopants at particular stages of film growth we are able to control their position within the film, and with respect to the oxide surface. Even if the dopants are in the surface region but below the outermost surface, STM can tell its presence. Figure 7 shows an image of Modoped $\mathrm{CaO}(100)$, which exhibits characteristic ring structures on the oxide surface. The surface density of these rings thereby varies with the number of Mo dopants embedded in the oxide matrix. Interestingly, the surface plane itself is perfect in all cases and no atom-size defects are identified in the ring centers. To connect the ring features in STM with Mo dopants in the lattice, we have changed the Mo concentration by annealing the films to different temperatures (Fig. 7b) thus increasing Mo diffusion into the films. Indeed, the density of ring structures was found to rise from $5 \times 10^{11}$ to $5 \times 10^{12} \mathrm{~cm}^{-2}$ when going from lowto high-temperature films. In the latter case, the rings overlapped without visible interference, suggesting that features seen in the STM originate indeed from isolated species in the oxide matrix. The ring features in STM can be explained with charging events of the $\mathrm{Mo}^{2+}$ dopants in the tip electric field, a mechanism that has been identified for semiconducting and organic layers before $[15,39,40]$.

Conclusive evidence for the nature of the rings comes from a careful analysis of their diameter in dependence on the tunneling parameters (Fig. 8) [41]. The ring structures arises due to band bending in the electric field of the STM tip which locally increases the energy of the dopant electronic states with respect to the unperturbed oxide electronic structure away from the tip. As schematically shown in Fig. 9, the Mo dopants charge up when the local band shift at the dopant position matches the binding energy of the highest occupied Mo donor level with respect to the oxide conduction band. At this moment, the bound Mo electron is pushed into the $\mathrm{CaO}$ conduction band and delocalizes over an extended $\mathrm{CaO}$ region. As a result, the positive charge at the Mo donor increases, which in turn produces an attractive Coulomb potential around the impurity and increases the available state density in the oxide surface. Electrons from the tip consequently find more final states for tunneling and a circular region around the donor appears with enhanced contrast. Simultaneously, a sharp ring becomes visible in the conductance maps due to the sudden rise of the accessible $\mathrm{CaO}$ state density upon charging (Fig. 8). The deviation of the perturbed region from an ideal circle thereby reflects the asymmetry of the tip apex, hence radial differences in the band 
bending. Note that the dopants at the metal oxide interface always transfer their electrons into the substrate (Fig. 9).

Summarizing the mechanism, the ring structures observed on $\mathrm{CaO}$ thin films can be connected to temporary charging events of Mo donors embedded in the oxide lattice. The rings develop as $\mathrm{Mo}^{2+}$ ions in a near surface region transfer their top-most electron to the $\mathrm{CaO}$ conduction band in response to the local field of the STM tip. We expect that such a promotion occurs not only in presence of an external stimulus (e.g. the tip electric field), but can be triggered also by electron-accepting molecules bound to the surface. We will discuss such a scenario for oxygen in the following section.

Figure 10 displays STM images of atomically flat, doped $\mathrm{CaO}(001)$ films before and after exposure to $\mathrm{O}_{2}$ [18]. The adsorbates are clearly discernible as circular depressions of $0.6 \AA$ depth and $10 \AA$ diameter in empty-state images. Exposing them to electrons from the STM tip verifies their molecular nature, as the adsorbates consecutively split into pairs of identical minima being assigned to the respective $\mathrm{O}$ atoms. Whereas a mean $\mathrm{O}-\mathrm{O}$ distance of $10-15 \AA$ is observed directly after dissociation, this value increases over time due to the repulsive character of the $\mathrm{O}-\mathrm{O}$ interaction on the $\mathrm{CaO}$ support. The two types of oxygen, atomic versus molecular, can be distinguished also via the pronounced topographic contrast of the molecule that contrasts against the "sombrero" shape of the atomic configuration.

Both, oxygen atoms and molecules, show a distinct bias dependence in the STM images. While the molecules always appear as pronounced depressions in the surface (depth $50 \mathrm{pm}$ ), the atoms are less deep ( $25 \mathrm{pm})$ and develop a bright ring around the minimum with increasing bias. The final assignment of the two species is made with STM manipulation experiments, in which the molecule is split into its atomic components with a $4.0 \mathrm{~V}$ bias pulse to the tip. The splitting procedure is only successful for the deep depressions, which are consequently assigned to the molecular species. No change in the STM appearance is revealed for the sombrero-type species, which are therefore related to single oxygen atoms.

The $\mathrm{O}_{2}$ adsorption efficiency strongly depends on the concentration of the Mo dopants. This becomes evident in Fig. 11, which displays weakly and strongly doped CaO films after exposure to $5 \mathrm{~L} \mathrm{O}_{2}$ at $20 \mathrm{~K}$. Whereas the Mo-poor film is almost unable to bind oxygen, an $\mathrm{O}_{2}$ concentration of $\sim 10^{17} \mathrm{~m}^{-2}$ is determined for the Mo-rich support, suggesting a crucial role of the dopants for binding. To correlate the Mo concentration with the reactivity of $\mathrm{CaO}$ 
towards oxygen, we use the position of the oxide conduction band with respect to the Fermi level as descriptor. The band position undergoes a downshift with increasing dopant concentration in the matrix, reflecting the presence of filled electronic states high in the $\mathrm{CaO}$ band gap (n-type conductivity) (Fig. 11). We now observe a steep onset in the $\mathrm{O}_{2}$ adsorption probability when the band edge drops below $3.0 \mathrm{eV}$, while films with a band position beyond $4.0 \mathrm{eV}$ are unable to bind oxygen. Apparently, dopants that are able to donate electrons into the $\mathrm{O}_{2}$ species are responsible for the molecular activation. This idea is supported by our observations that after removing $\mathrm{O}_{2}$ molecules from the surface, e.g. via a bias pulse with the tip, the typical charging ring of a Mo donor becomes visible in the STM images (as shown in Fig. 7). Apparently, there is a spatial correlation between Mo donors in the oxide matrix and the binding positions for $\mathrm{O}_{2}$ molecules, which enables a charge transfer out of the donor and the formation of super-oxo $\left(\mathrm{O}_{2}{ }^{-}\right)$species.

Such a scenario is, indeed, supported by various spectroscopic investigations. In XPS, we find the $\mathrm{Ca} 2 \mathrm{p}$ and $\mathrm{O} 1 \mathrm{~s}$ binding energies to shift downwards by $0.2 \mathrm{eV}$ after dosing $\mathrm{O}_{2}$ onto the films. The same trend is revealed for the band positions revealed by STM conductance spectroscopy. Both shifts indicate a workfunction increase, driven by an electron transfer from the dopants into the surface oxygen. The reverse effect, hence $\mathrm{O}_{2}$ desorption, elucidates even the magnitude of the workfunction shift $(\Delta \varphi)$ and thus of the charge transfer. For this purpose, we have monitored the position of characteristic vacuum states above one and the same $\mathrm{CaO}$ region with and without adsorbed oxygen (Fig. 12). We find a rigid downshift of the states by $0.35 \mathrm{eV}$, being explained with the removal of vertical $\mathrm{Mo}^{\delta^{+}}-\mathrm{O}_{2}^{\delta^{-}}$dipoles upon oxygen desorption. The Helmholtz formula $\Delta \varphi=$ $\frac{e}{\varepsilon_{0} \varepsilon_{r}} \mu_{a d} N_{a d}$ allows us to obtain an estimate of the dipole strength $\mu_{a d}$ of the chargetransfer pairs. For an $\mathrm{O}_{2}$ concentration of $\mathrm{N}_{a d}=10^{17} \mathrm{~m}^{-2}$ and a $\mathrm{CaO}$ dielectric constant of $\varepsilon_{r}$ $=10$, we calculate a dipole moment of $3 \times 10^{-28} \mathrm{C} \cdot \mathrm{m}$, a value that is compatible with transferring one electron from a Mo ion in the $6^{\text {th }}$ subsurface layer to an ad-oxygen. $A$ last indication for $\mathrm{O}_{2}^{-}$formation on doped $\mathrm{CaO}$ films comes from the facile dissociation of the molecules, which proceeds with almost $100 \%$ probability when injecting $4.0 \mathrm{~V}$ electrons from the tip (1min @ 20 pA). The bond cleavage occurs as a second electron enters the antibonding states of the already weakened super-oxo species. 
The anticipated electron transfer between Mo donors and $\mathrm{O}_{2}$ acceptors is corroborated by DFT calculations performed with a B3LYP+D hybrid functional [18]. On non-doped $\mathrm{CaO}(001)$, a neutral $\mathrm{O}_{2}$ molecule binds with $13 \mathrm{~kJ} / \mathrm{mol}$ to a Ca-Ca bridge position, whereas $\mathrm{Ca}^{2+}$ top sites are less preferred. In contrast, an $\mathrm{O}_{2}^{-}$species bound with $98 \mathrm{~kJ} / \mathrm{mol}$ to the same bridge site forms when a $\mathrm{Mo}^{3+}$ ion is present in the third subsurface layer. The charge transfer to the oxygen would be even more favorable for $\mathrm{Mo}^{2+}$ donors that have a lower ionization potential. Also the computed $\mathrm{O}-\mathrm{O}$ bond elongation from 121 to $134 \mathrm{pm}$ and the softening of the $0-0$ stretching frequency to $1193 \mathrm{~cm}^{-1}$ evidences the formation of super-oxo species on the surface of Mo-doped CaO. Finally, a decrease of the apparent $\mathrm{O}-\mathrm{O}$ dissociation barrier from $110 \mathrm{~kJ} / \mathrm{mol}$ for neutral $\mathrm{O}_{2}$ on pristine $\mathrm{CaO}$ to $66 \mathrm{~kJ} / \mathrm{mol}$ for super-oxo species on doped films is computed with the PBE $+\mathrm{D}$ functional. Apparently, $\mathrm{O}_{2}$ molecules may be activated to form super-oxo species even on smooth, defect-free surfaces of a non-reducible oxide, when dopants are present in the bulk. The $\mathrm{O}_{2}{ }^{-}$species is bound with about $100 \mathrm{~kJ} / \mathrm{mol}$, hence stable at room temperature, and prone to dissociate into atomic oxygen on the doped surface. We suggest that such species may play a decisive role in activating even inert hydrocarbons, e.g. methane, on wide-gap oxide surfaces. First realization of the doping concept was demonstrated by using Fe-doped MgO powder samples for oxidative coupling of methane [42].

\section{Synopsis}

We have discussed two examples for model studies on oxidation catalysis. Vanadia nanoparticles on ceria comprise a well-defined model to uniquely correlate reactivity to methanol oxidation, and conclusions were obtained for real catalyst systems. We show in the second case study that dopants of transition metal ions in simple oxide lattices, such as $\mathrm{CaO}$, may be instrumental in transferring electrons to electron traps on the surface, i.e. oxygen molecules, or electronegative metals, such as Au. This concept based on model studies may be transferred to catalysis on real systems. Our experiments demonstrate that studies on model systems may be useful to improve the general understanding of catalytic processes as well as for catalyst design. 


\section{Acknowledgment}

We thank our coworkers, past and present, for their important contributions to the results presented here. Their names are listed in the references. We are grateful for financial support through the cluster of excellence of the German Science Foundation (DFG) "UniCat", administrated through the TU Berlin, as well as to the Fonds der Chemischen Industrie. 


\section{References}

1 Ertl G, Knözinger H, Schueth F, Weitkamp J (2008) Handbook of Heterogeneous Catalysis. 2., compl. rev. and enlarged ed. edn. VCH, Weinheim

2 Freund HJ (1997) Adsorption of Gases on Complex Solid Surfaces. Angew Chem Int Ed 36 (5):452-475. doi:10.1002/anie.199704521

3 Freund H-J, Goodman DW (2008) Ultrathin Oxide Films. In: Ertl G, Knözinger H, Schüth F, Weitkamp J (eds) Handbook of Heterogeneous Catalysis, vol 3. 2. edn. Wiley-VCH Verlagsgesellschaft mbH, Weinheim, pp 1309-1338

4 Freund HJ (2010) Model Studies in Heterogeneous Catalysis. Chem Eur J 16 (31):93849397. doi:10.1002/chem.201001724

5 Freund H-J, Heyde M, Nilius N, Schauermann S, Shaikhutdinov S, Sterrer M (2013) Model Studies on Heterogeneous Catalysts at the Atomic Scale: From Supported Metal Particles to Two-dimensional Zeolites. J Catal accepted. doi:10.1016/j.jcat.2013.06.007

6 Libuda J, Freund H-J (2005) Molecular beam experiments on model catalysts. Surf Sci Rep 57 (7-8):157-298

7 Freund H-J, Pacchioni G (2008) Oxide ultra-thin films on metals: new materials for the design of supported metal catalysts. Chem Soc Rev 37 (10):2224-2242. doi:10.1039/b718768h

8 Pacchioni G, Freund H (2012) Electron Transfer at Oxide Surfaces. The MgO Paradigm: from Defects to Ultrathin Films. Chem Rev. doi:10.1021/cr3002017

9 Haber J (2008) Fundamentals of Hydrocarbon Oxidation. In: Ertl G, Knözinger H, Schüth F, Weitkamp J (eds) Handbook of Heterogeneous Catalysis. Wiley-VCH Verlag GmbH \& Co. KGaA, Weinheim. doi:10.1002/9783527610044.hetcat0170

10 Callahan JL, Grasselli RK (1963) A selectivity factor in vapor-phase hydrocarbon oxidation catalysis. AIChE J 9 (6):755-760. doi:10.1002/aic.690090610

11 Grasselli R (2001) Genesis of site isolation and phase cooperation in selective oxidation catalysis. Top Catal 15 (2-4):93-101. doi:10.1023/A:1016683117255

12 Sauer J (2008) C-H Bond Activation by Transition Metal Oxides. In: Morokuma K, Djamaladdin GM (eds) Computational Modeling for Homogeneous and Enzymatic Catalysis. Wiley-VCH Verlag GmbH \& Co. KGaA, Weinheim, pp 231-244. doi:10.1002/9783527621965.ch10

13 Ganduglia-Pirovano MV, Popa C, Sauer J, Abbott H, Uhl A, Baron M, Stacchiola D, Bondarchuk O, Shaikhutdinov S, Freund H-J (2010) Role of Ceria in Oxidative Dehydrogenation on Supported Vanadia Catalysts. J Amer Chem Soc 132 (7):23452349. doi:10.1021/ja910574h

14 Metiu H, Chrétien S, Hu Z, Li B, Sun X (2012) Chemistry of Lewis Acid-Base Pairs on Oxide Surfaces. J Phys Chem C 116 (19):10439-10450. doi:10.1021/jp301341t

15 Andersin J, Nevalaita J, Honkala K, Häkkinen H (2013) The Redox Chemistry of Gold with High-Valence Doped Calcium Oxide. Angew Chem Int Ed 52 (5):1424-1427. doi:10.1002/anie.201208443

16 Stavale F, Shao X, Nilius N, Freund H-J, Prada S, Giordano L, Pacchioni G (2012) Donor Characteristics of Transition-Metal-Doped Oxides: Cr-Doped MgO versus Mo-Doped CaO. J Am Chem Soc 134 (28):11380-11383. doi:10.1021/ja304497n

17 Baron M, Abbott H, Bondarchuk O, Stacchiola D, Uhl A, Shaikhutdinov S, Freund H-J, Popa C, Ganduglia-Pirovano Maria V, Sauer J (2009) Resolving the Atomic Structure of 
Vanadia Monolayer Catalysts: Monomers, Trimers, and Oligomers on Ceria. Angew Chem Int Ed 48 (43):8006-8009

18 Cui Y, Nilius N, Shao X, Baldofski M, Sauer J, Freund H-J (2013) Adsorption, Activation and Dissociation of Oxygen on Doped Oxides. Angew Chem Int Ed submitted

19 Wachs IE (1996) Raman and IR studies of surface metal oxide species on oxide supports: Supported metal oxide catalysts. Catal Today 27 (3-4):437-455.

doi:http://dx.doi.org/10.1016/0920-5861(95)00203-0

20 Deo G, Wachs IE, Haber J (1994) SUPPORTED VANADIUM-OXIDE CATALYSTS MOLECULAR STRUCTURAL CHARACTERIZATION AND REACTIVITY PROPERTIES. Crit ReV Surf Chem 4 (3-4):141-187

21 Khodakov A, Olthof B, Bell AT, Iglesia E (1999) Structure and catalytic properties of supported vanadium oxides: Support effects on oxidative dehydrogenation reactions. J Catal 181 (2):205-216. doi:10.1006/jcat.1998.2295

22 Martínez-Huerta MV, Deo G, Fierro JLG, Bañares MA (2008) Operando Raman-GC Study on the Structure-Activity Relationships in V 5+/CeO 2 Catalyst for Ethane Oxidative Dehydrogenation: The Formation of CeVO 4. J Phys Chem C 112 (30):1144111447. doi:10.1021/jp802827t

23 Olthof B, Khodakov A, Bell AT, Iglesia E (2000) Effects of support composition and pretreatment conditions on the structure of vanadia dispersed on $\mathrm{SiO}_{2}, \mathrm{Al}_{2} \mathrm{O}_{3}, \mathrm{TiO}_{2}$, $\mathrm{ZrO}_{2}$, and $\mathrm{HfO}_{2}$. J Phys Chem B 104 (7):1516-1528. doi:10.1021/jp9921248

24 Bañares MA, Martínez-Huerta M, Gao X, Wachs IE, Fierro JLG (2000) Identification and roles of the different active sites in supported vanadia catalysts by in situ techniques. In: Avelino Corma FVMSM, José Luis GF (eds) Studies in Surface Science and Catalysis, vol Volume 130. Elsevier, pp 3125-3130. doi:http://dx.doi.org/10.1016/S01672991(00)80502-9

25 Weckhuysen BM, Keller DE (2003) Chemistry, spectroscopy and the role of supported vanadium oxides in heterogeneous catalysis. Catal Today 78 (1-4):25-46.

doi:http://dx.doi.org/10.1016/s0920-5861(02)00323-1

26 Martínez-Huerta MV, Coronado JM, Fernández-García M, Iglesias-Juez A, Deo G, Fierro JLG, Bañares MA (2004) Nature of the vanadia-ceria interface in $\mathrm{V}^{5+} / \mathrm{CeO}_{2}$ catalysts and its relevance for the solid-state reaction toward $\mathrm{CeVO}_{4}$ and catalytic properties. J Catal 225 (1):240-248. doi:http://dx.doi.org/10.1016/i.jcat.2004.04.005

27 Vohs JM, Feng T, Wong GS (2003) Comparison of the reactivity of high-surface area, monolayer vanadia/ceria catalysts with vanadia/CeO2(111) model systems. Catal Today 85 (2-4):303-309

28 Pfau A, Schierbaum KD (1994) The electronic structure of stoichiometric and reduced $\mathrm{CeO}_{2}$ surfaces: an XPS, UPS and HREELS study. Surf Sci 321 (1-2):71-80. doi:http://dx.doi.org/10.1016/0039-6028(94)90027-2

29 Kropp T, Sauer J (2013). to be published

30 Beck B, Harth M, Hamilton NG, Carrero C, Uhlrich JJ, Trunschke A, Shaikhutdinov S, Schubert H, Freund H-J, Schlögl R, Sauer J, Schomäcker R (2012) Partial oxidation of ethanol on vanadia catalysts on supporting oxides with different redox properties compared to propane. J Catal 296 (0):120-131.

doi:http://dx.doi.org/10.1016/j.jcat.2012.09.008

31 Guimond S, Abu Haija M, Kaya S, Lu J, Weissenrieder J, Shaikhutdinov S, Kuhlenbeck H, Freund HJ, Dobler J, Sauer J (2006) Vanadium oxide surfaces and supported vanadium oxide nanoparticles. Top Catal 38 (1-3):117-125. doi:10.1007/s11244-006-0076-8 
32 Dillmann B, Rohr F, Seiferth O, Klivenyi G, Bender M, Homann K, Yakovkin IN, Ehrlich D, Bäumer M, Kuhlenbeck $\mathrm{H}$, Freund $\mathrm{HJ}$ (1996) Adsorption on a polar oxide surface: $\mathrm{O}_{2}$, $\mathrm{C}_{2} \mathrm{H}_{4}$ and $\mathrm{Na}$ on $\mathrm{Cr}_{2} \mathrm{O}_{3}(0001) / \mathrm{Cr}(110)$. Faraday Discuss 105:295-315. doi:10.1039/fd9960500295

33 Strömberg D (1992) The bonding and migration of an O atom on a CaO(100) surface: a theoretical study. Surf Sci 275 (3):473-481. doi:http://dx.doi.org/10.1016/00396028(92)90820-V

34 Nygren MA, Pettersson LGM (1994) Theoretical modelling of metal oxides. Influence of field strength on atomic oxygen adsorption and a simple model reaction: Oads $+\mathrm{CO} \rightarrow$ CO2. Chem Phys Lett 230 (4-5):456-462. doi:http://dx.doi.org/10.1016/00092614(94)01171-0

35 König T, Simon GH, Rust HP, Pacchioni G, Heyde M, Freund HJ (2009) Measuring the Charge State of Point Defects on MgO/Ag(001). J Am Chem Soc 131 (48):17544-17545. doi:10.1021/ja908049n

36 Shao X, Prada S, Giordano L, Pacchioni G, Nilius N, Freund H-J (2011) Tailoring the Shape of Metal Ad-Particles by Doping the Oxide Support. Angew Chem Int Ed 50 (48):11525-11527. doi:10.1002/anie.201105355

37 Stavale F, Nilius N, Freund H-J (2012) Cathodoluminescence of near-surface centres in $\mathrm{Cr}$-doped $\mathrm{MgO}(001)$ thin films probed by scanning tunnelling microscopy New J Phys 14:033006. doi:http://iopscience.iop.org/1367-2630/14/3/033006/

38 Benia HM, Myrach P, Gonchar A, Risse T, Nilius M, Freund HJ (2010) Electron trapping in misfit dislocations of MgO thin films. Phys Rev B 81:241415.

doi:http://link.aps.org/doi/10.1103/PhysRevB.81.241415

39 Lunsford JH (1995) The Catalytic Oxidative Coupling of Methane. Angew Chem Int Ed 34 (9):970-980. doi:10.1002/anie.199509701

40 Stipe BC, Rezaei MA, Ho W, Gao S, Persson M, Lundqvist BI (1997) Single-Molecule Dissociation by Tunneling Electrons. Phys Rev Lett 78 (23):4410-4413

41 Cui Y, Nilius N, Freund H-J, Prada S, Giordano L, Pacchioni G (2013) Controlling the Charge State of Singe Mo-Dopants in a CaO Thin Film. submitted

42 Schwach P, Willinger MG, Trunschke A, Schlögl R (2013) Methane coupling over magnesium oxide: how doping can work. Angew Chem Int Ed submitted

43 Cui Y, Nilius N, Shao X, Baldofski M, Sauer J, Freund H-J (2013) Adsorption, Activation and Dissociation of Oxygen on Doped Oxides. in preparation 


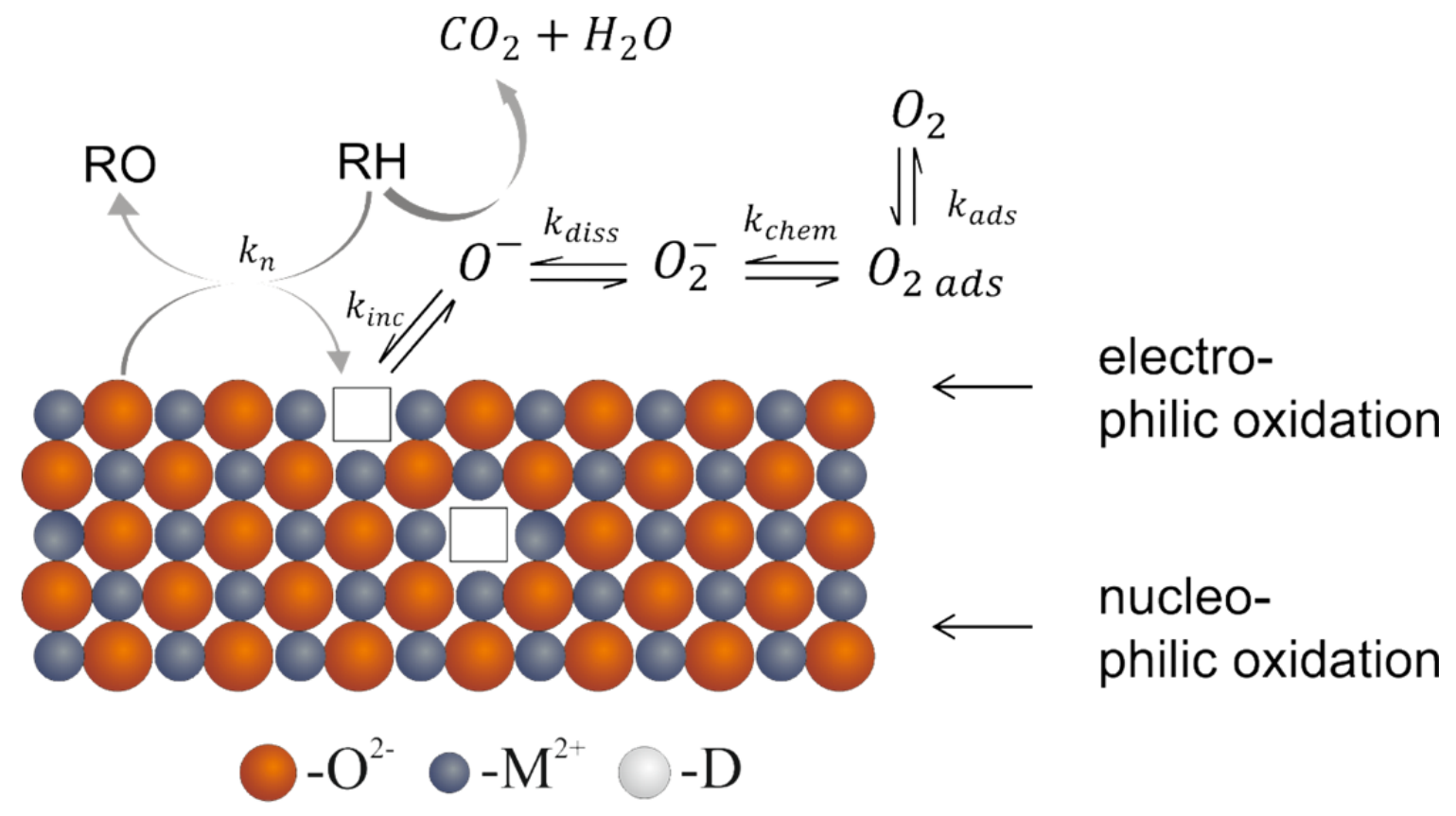

Figure 1: Mechanism of the oxidation of a hydrocarbon molecule to an aldehyde over an oxide catalyst (adapted from figure 2 from ref. [9]).
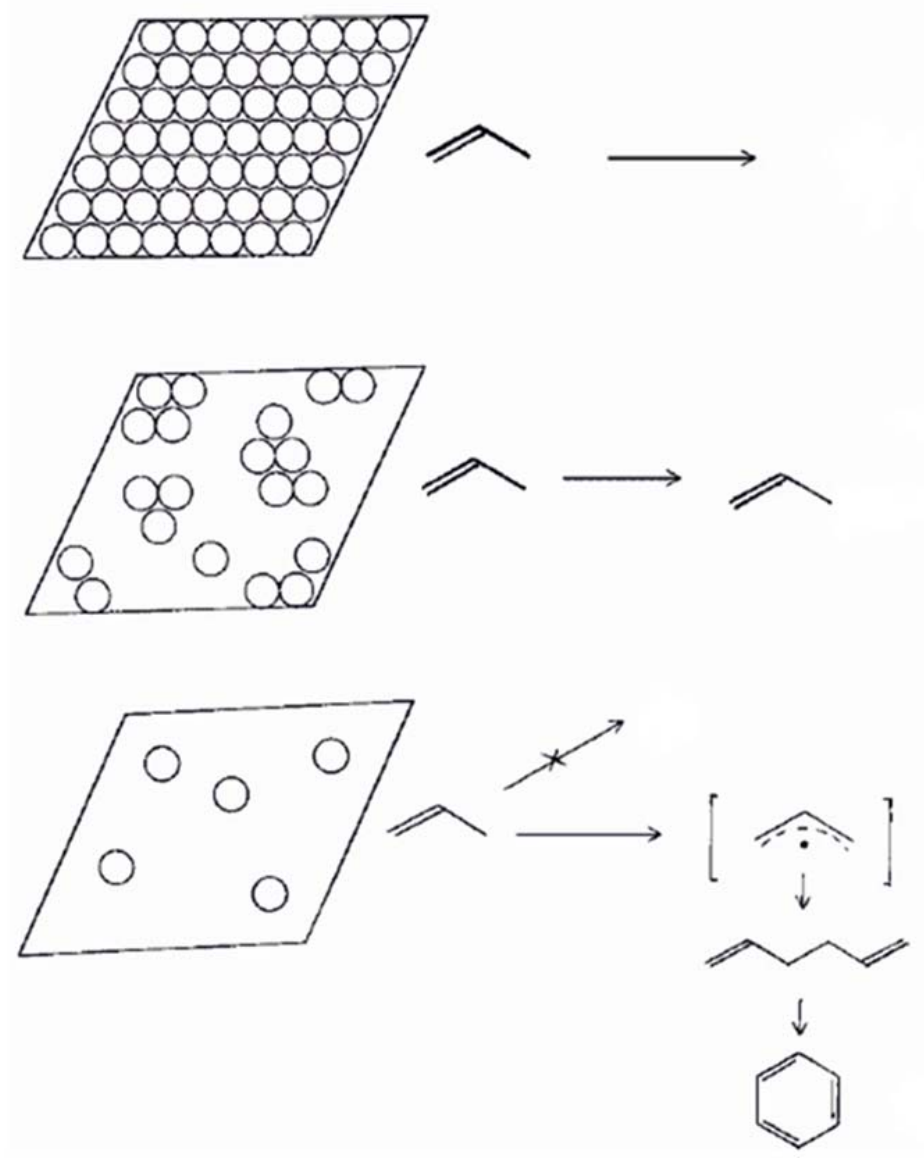

Figure 2: Site isolation principle. Schema of active lattice oxygen arrangements on hypothetical surfaces. Anticipated reaction paths of propylene upon contact with these surfaces[10][11]. 


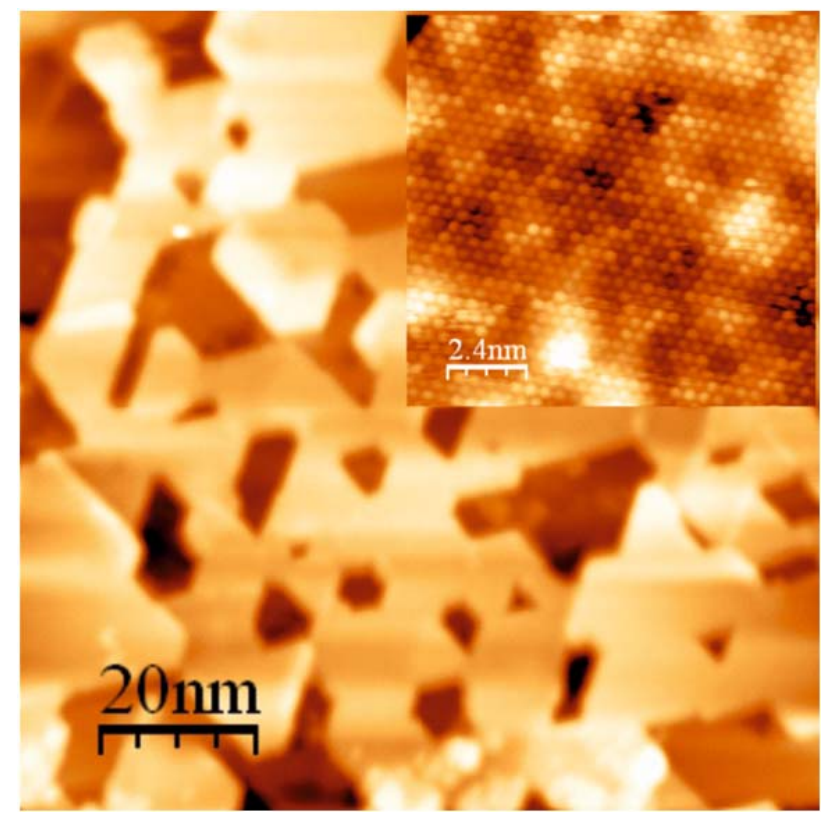

Figure 3: Large scale STM image of a $\mathrm{CeO}_{2}(111)$ surface revealing its morphology and its atomic structure (inset).
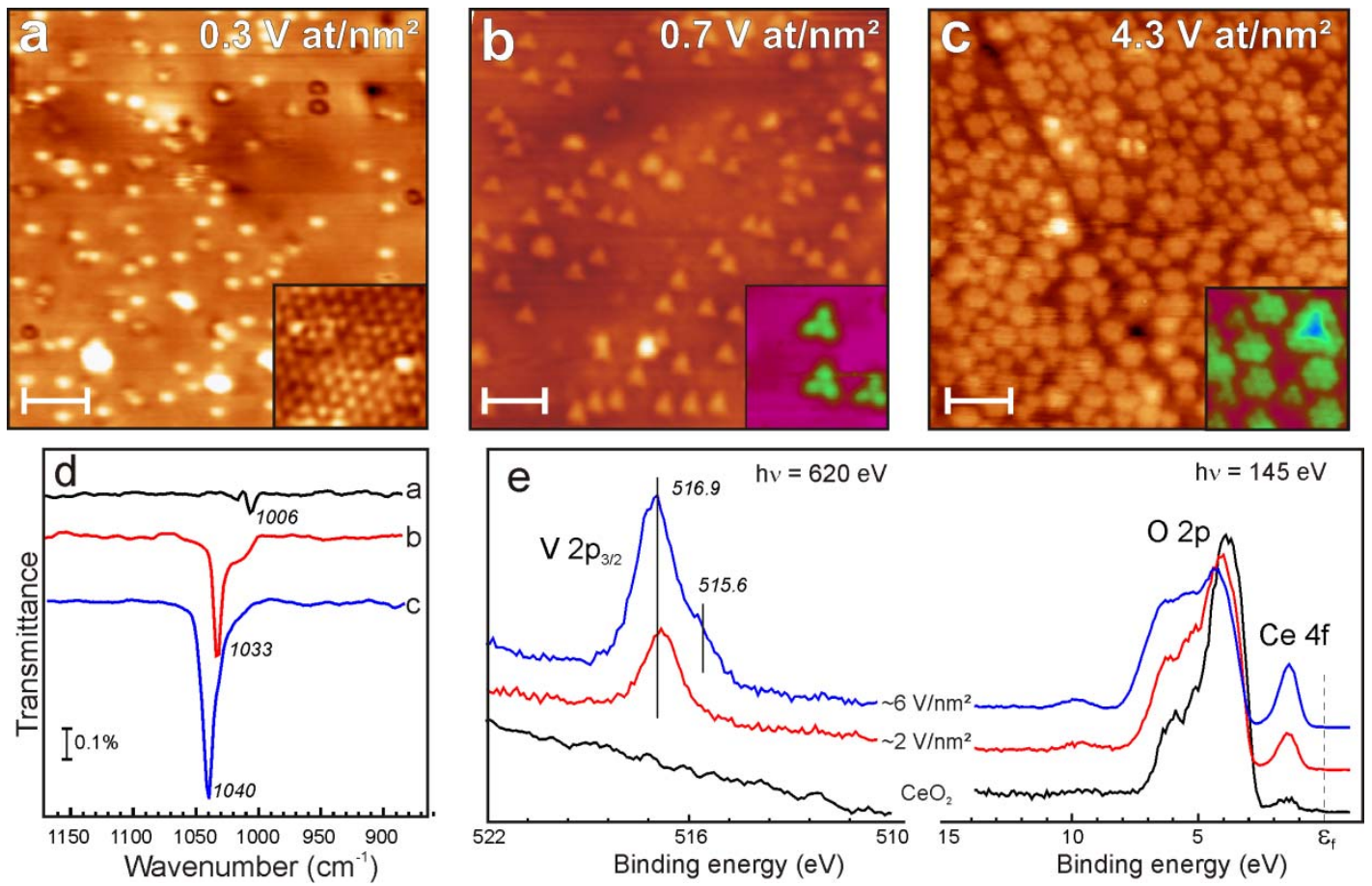

Figure 4: (a-c) STM images of $\mathrm{VO}_{x} / \mathrm{CeO}_{2}(111)$ for various vanadia loadings as indicated. Sample (a) was annealed to $300 \mathrm{~K}$, while samples (b) and (c) were additionally annealed in UHV to $700 \mathrm{~K}$. The insets highlight the atomic structure of the vanadia deposits. (The scale bars are $3 \mathrm{~nm}$. Tunneling bias is $3 \mathrm{~V}$; tunneling current is $0.02 \mathrm{nA}(\mathrm{a}), 0.01 \mathrm{nA}(\mathrm{b})$, and $0.10 \mathrm{nA}$ (c)). d) IRA spectra of the vanadyl $(V=O)$ stretching region for the corresponding STM images (a-c). e) Photoelectron spectra (at photon energies as indicated) for two loadings of vanadia on $\mathrm{CeO}_{2}(111)$ compared to a pristine $\mathrm{CeO}_{2}(111)$ thin film. [17] 


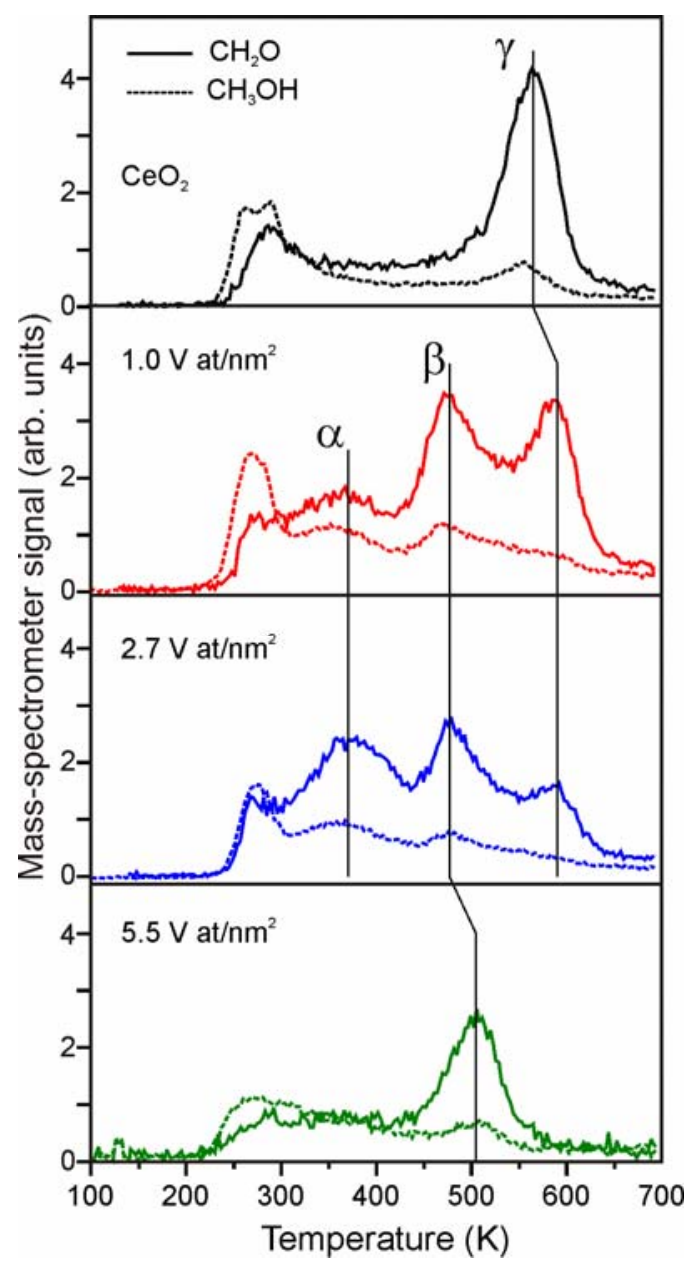

Figure 5: TPD spectra for $5 \mathrm{~L}$ of $\mathrm{CH}_{3} \mathrm{OH}$ adsorbed at $300 \mathrm{~K}$ on $\mathrm{CeO}_{2}(111)$ and $\mathrm{VOx} / \mathrm{CeO}_{2}(111)$ surfaces at vanadia loadings as indicated. Dashed lines indicate the raw signal for $\mathrm{CH}_{3} \mathrm{OH}$ (31 amu), whereas solid lines indicate formaldehyde $\left(\mathrm{CH}_{2} \mathrm{O}\right)$ production (29 amu, corrected for the methanol cracking pattern). Signal intensity below $300 \mathrm{~K}$ is assigned to the tail of $\mathrm{CH}_{3} \mathrm{OH}$ monolayer desorption. [13] (Reprinted with permission from Ganduglia-Pirovano MV, Popa C, Sauer J, Abbott H, Uhl A, Baron M, Stacchiola D, Bondarchuk O, Shaikhutdinov S, Freund H-J (2010) Role of Ceria in Oxidative Dehydrogenation on Supported Vanadia Catalysts. J Amer Chem Soc 132 (7):2345-2349 Copyright (2010) American Chemical Society.) 


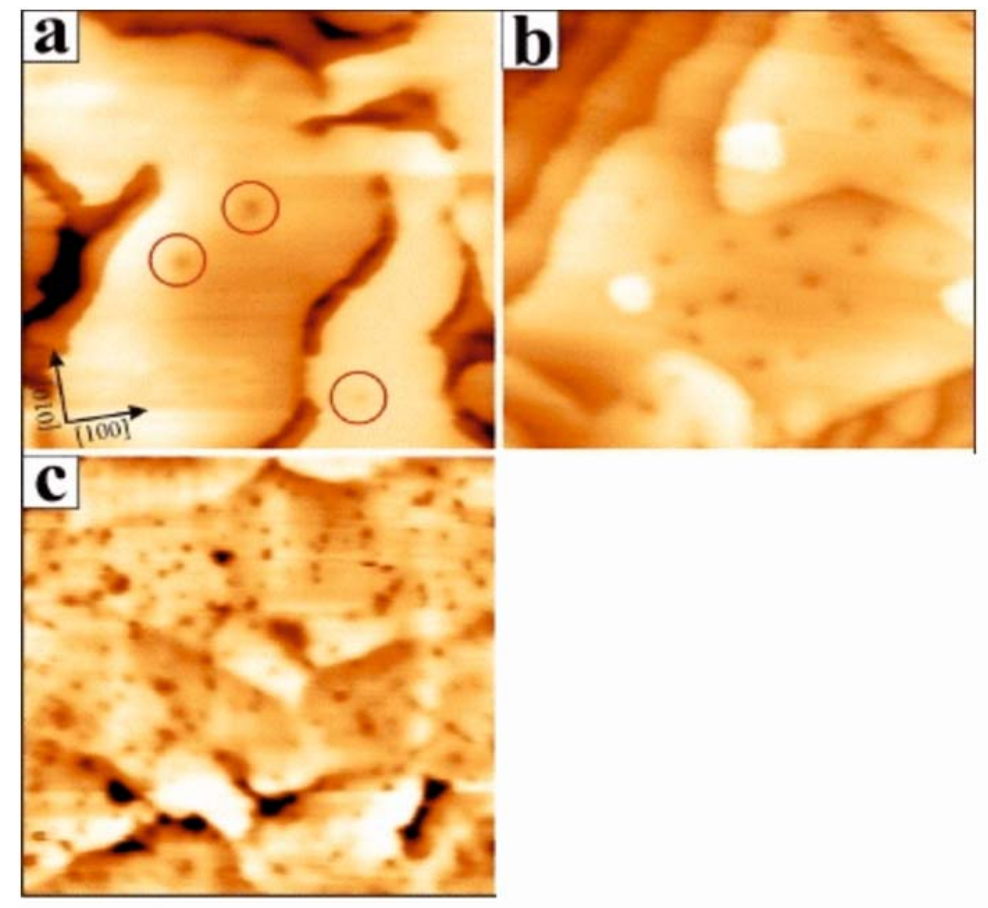

Figure 6: STM topographic images of $\mathrm{Cr} / \mathrm{Mg}$ mixed oxides on $\mathrm{Mo}(001)$ after annealing to $1000 \mathrm{~K}\left(35 \times 35 \mathrm{~nm}^{2}, 1.5 \mathrm{~V}\right)$. The $\mathrm{Cr}$ concentration rises from (a) $0.05 \%$, (b) $0.5 \%$ to (c) $1 \%$, producing an increasing number of atom-sized holes in the surfaces [37].

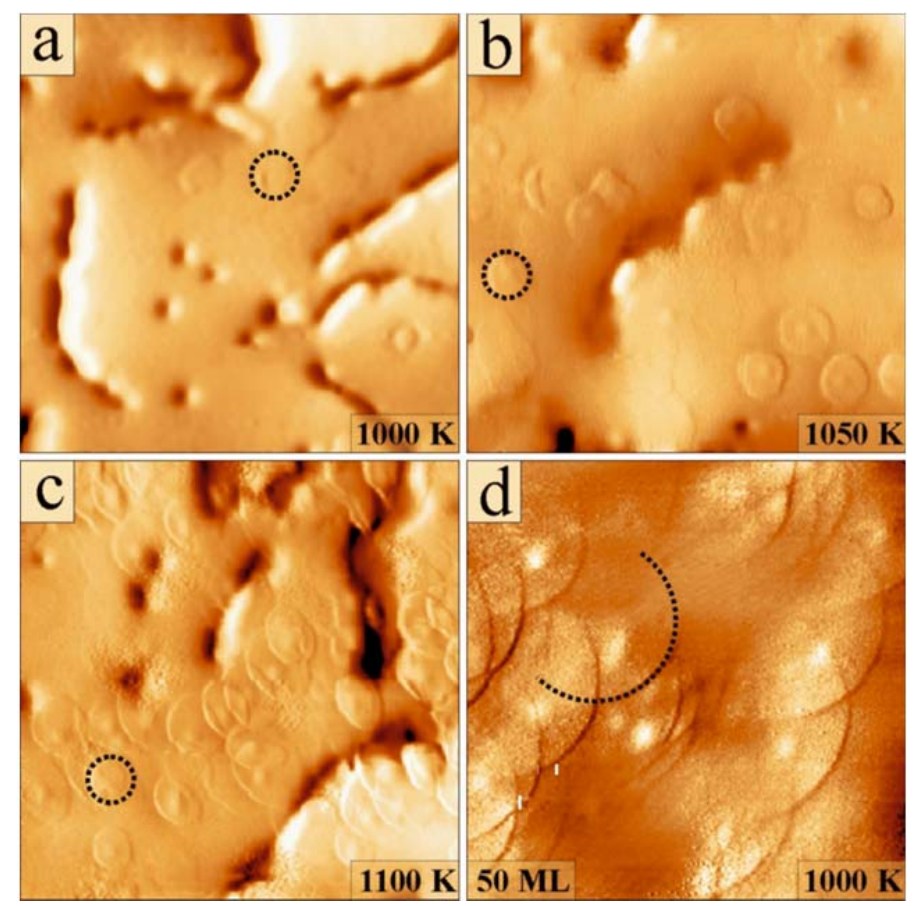

Figure 7a: (a-c) STM images of $25 \mathrm{ML} \mathrm{CaO}$ annealed to the given temperatures $\left(30 \times 30 \mathrm{~nm}^{2}\right.$, $2.6 \mathrm{~V}$ ). Note the increasing number of charging rings (see broken circle) upon annealing. (d) On $50 \mathrm{ML}$ thick films, the diameter of charging rings is larger due to the bad dielectric screening $\left(30 \times 30 \mathrm{~nm}^{2}, 4.4 \mathrm{~V}\right)$ [41]. 


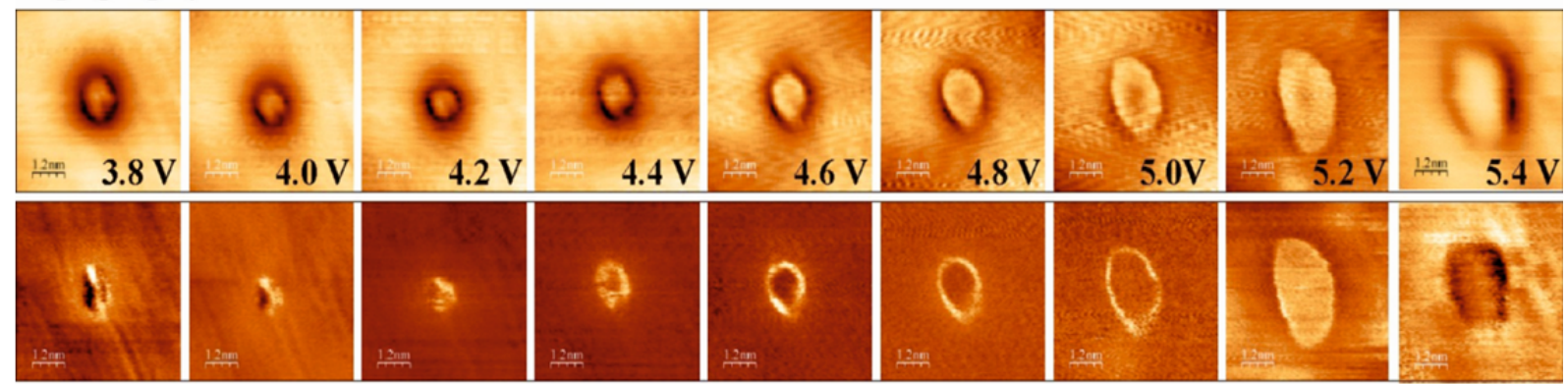

\section{Differential Conductance}

Figure 8: Topographic and $\mathrm{dl} / \mathrm{dV}$ maps of a single Mo donor measured as function of bias voltages. The asymmetry of the charging rings reflects the deviation of the tip apex from a perfect sphere $\left(5 \times 5 \mathrm{~nm}^{2}\right)$ [41].

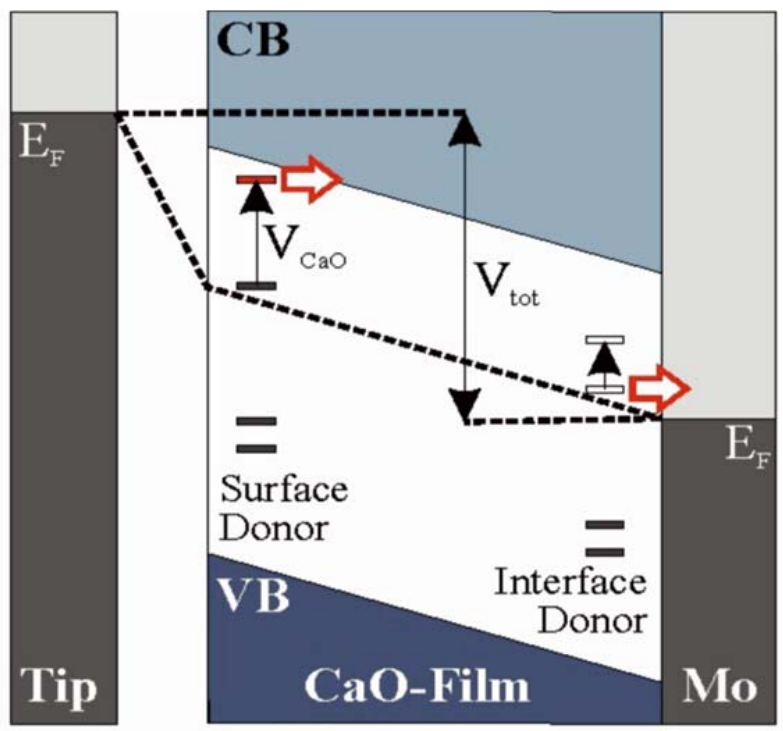

Figure 9: Potential diagram of a STM junction containing a thick $\mathrm{CaO}$ film. The oxide bands bend upward in the tip-electric field, which eventually leads to an electron transfer from the $\mathrm{Mo}^{2+} \mathrm{HO}-\mathrm{MO}$ into a $\mathrm{CaO}$ conduction state [41]. 

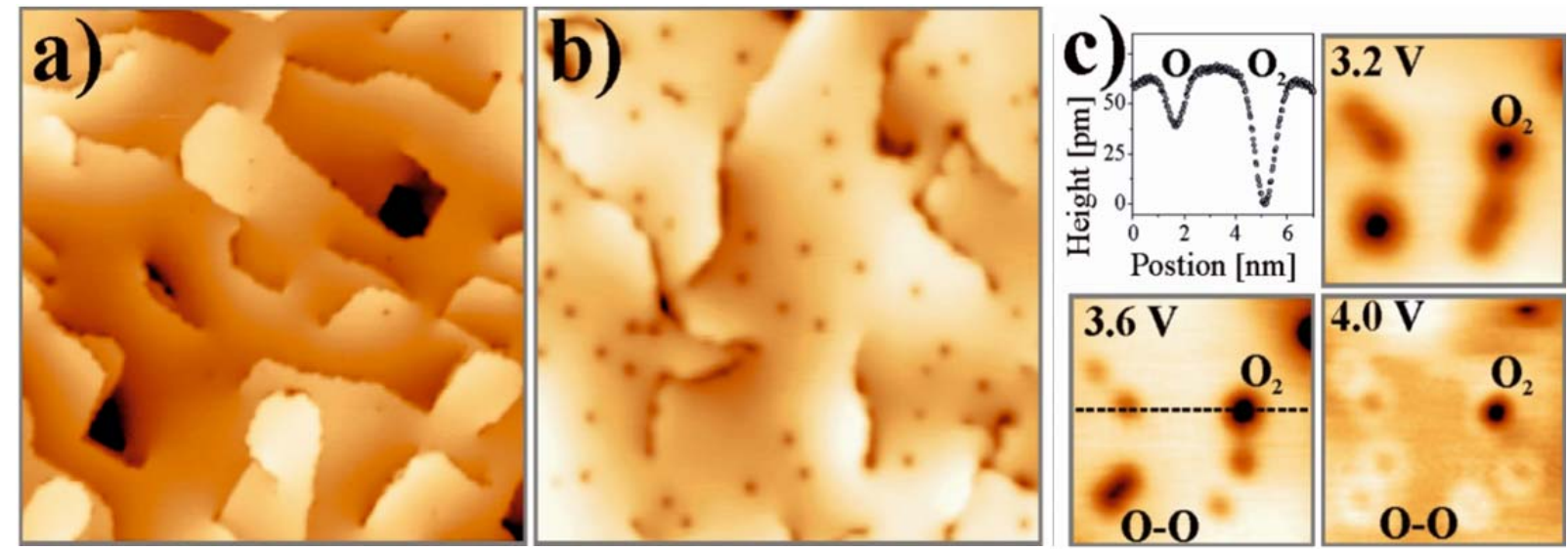

Figure 10: STM images of (a) a pristine $25 \mathrm{ML} \mathrm{CaO(001)} \mathrm{film}\left(4.0 \mathrm{~V}, 80 \times 80 \mathrm{~nm}^{2}\right)$ and (b) films after $\mathrm{O}_{2}$ exposure of $5 \mathrm{~L} @ 20 \mathrm{~K}$ (c) Height profile and bias-dependent images of oxygen molecules and atoms. While atoms appear with pronounced sombrero shapes at elevated bias, the molecular species are imaged as deep depressions in the surface [43].
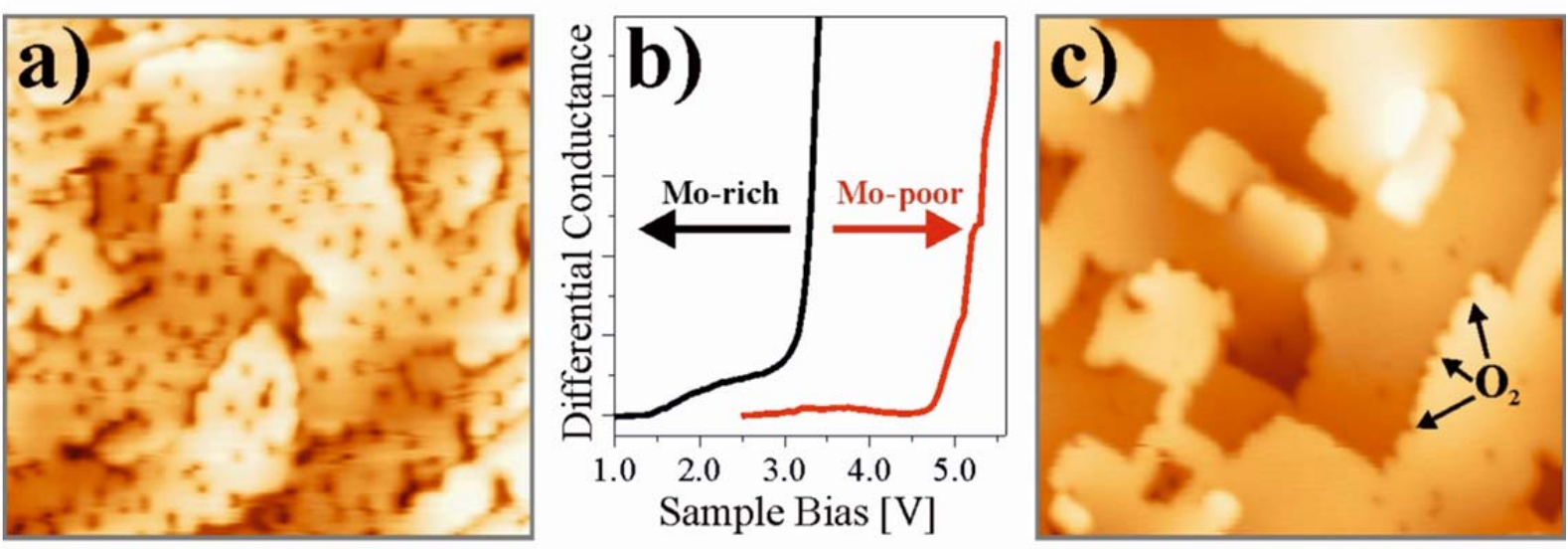

Figure 11: (a,c) STM images of strongly and weakly-doped $\mathrm{CaO}$ films after exposure to $5 \mathrm{~L} \mathrm{O}_{2}$ $@ 20 \mathrm{~K}\left(40 \times 40 \mathrm{~nm}^{2}\right)$. The $\mathrm{O}_{2}$ adsorption probability depends on the position of the $\mathrm{CaO}$ conduction band edge, as measured with $\mathrm{dl} / \mathrm{dV}$ spectroscopy (b). Step edges are preferred $\mathrm{O}_{2}$ binding sites only on weakly doped films [43]. We find the Ca2p and $01 \mathrm{~s}$ binding energies to shift downwards by $0.2 \mathrm{eV}$ after dosing $\mathrm{O}_{2}$. 

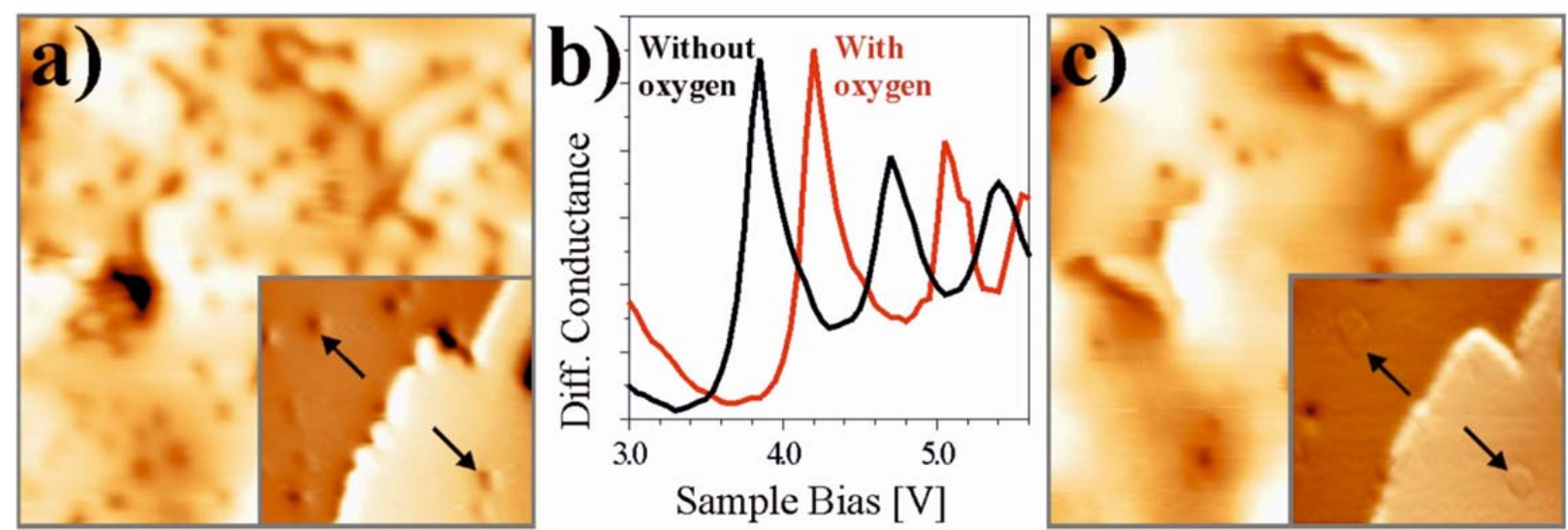

Figure 12: Identical $\mathrm{CaO}$ region before and after $\mathrm{O}_{2}$ desorption with the tip $(3.3 \mathrm{~V}, 27 \times 27$ $\mathrm{nm}^{2}$ ). The inset shows a selected area with higher resolution, revealing the appearance of dopant-related ring structures below the oxygen molecules (see arrows) $(4.0 \mathrm{~V}, 17 \times 17$ $\mathrm{nm}^{2}$ ). (b) STM conductance spectra showing the downshift of $\mathrm{CaO}$ vacuum states after $\mathrm{O}_{2}$ desorption from the surface [43]. 